\title{
sciendo
}

\author{
Current Issues in Pharmacy and Medical Sciences \\ Formerly ANNALES UNIVERSITATIS MARIAE CURIE-SKLODOWSKA, SECTIO DDD, PHARMACIA \\ journal homepage: http://www.curipms.umlub.pl/
}

\section{Hypoglycemic activity of Phaseolus vulgaris (L.) aqueous extract in type 1 diabetic rats}

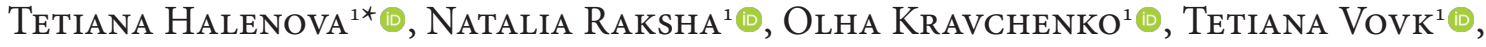

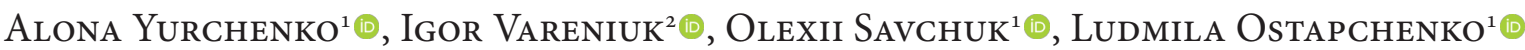 \\ ${ }^{1}$ Department of Biochemistry Educational an d Scientific Center "Institute of Biology and Medicine" Taras Shevchenko National University \\ of Kyiv, 64/13 Volodymyrska Street, 01601 Kyiv, Ukraine \\ ${ }^{2}$ Department of Cytology Educational and Scientific Center "Institute of Biology and Medicine" Taras Shevchenko National University \\ of Kyiv, 64/13 Volodymyrska Street, 01601 Kyiv, Ukraine
}

\section{ARTICLE INFO \\ Received 19 February 2019 \\ Accepted 24 April 2019}

\section{Keywords:}

aqueous extract,

Phaseolus vulgaris,

hypoglycemic activity,

diabetes mellitus.

\begin{abstract}
The aim of the present study was to evaluate the hypoglycemic activity of the aqueous extract from the fruit walls of Phaseolus vulgaris pods and to examine the potential mechanism underlying the improvement of the glycemic level. In the course of the study, diabetes mellitus was induced in rats with a single intraperitoneal injection of streptozotocin (45 mg.kg-1 b.w.). Diabetic and control rats were then orally administered with a singledose or repeated-dose (28 day) of $P$. vulgaris extract $\left(200 \mathrm{mg} \cdot \mathrm{kg}^{-1}\right)$. Results show that the extract was found to possess significant hypoglycemic activity, and the study of glucose utilization by isolated rat hemidiaphragm suggests that the aqueous extract may enhance the peripheral utilization of glucose. The subsequent experiments have revealed that the P. vulgaris extract could increase glucose transporter 4 (GLUT-4) content in skeletal muscle cells of control and diabetic rats. Our data also indicate that the P. vulgaris extract did not affect the content of the insulin receptor, but significantly reduced the total tyrosine kinase activity in skeletal muscle cells of both experimental groups of rats. The present results clearly indicated that $P$. vulgaris extract may be beneficial for reducing hyperglycemia through its potency in regulation of glucose utilization via GLUT-4, but the current mechanism remains to be unidentified.
\end{abstract}

\section{INTRODUCTION}

In recent years, the number of diseases associated with metabolic disorders has significantly increased. Diabetes mellitus (DM)A has kept a stable primacy among them. The International Diabetes Federation has reported that, currently, 415 million adults aged 20-79 years suffer from diabetes all over the world, and the number is expected to increase to 642 million by 2040 [1]. This disappointing statistics shows that despite the good awareness and new developments in treatment and prevention of diabetes, the question of its effective therapy remains unresolved.

DM is characterized by high blood glucose level that results from either defects in insulin secretion (type 1 diabetes) or impairments in insulin actions (type 2 diabetes) [2]. Chronic hyperglycemia is recognized to be the most important risk factor in development of disabling and

\footnotetext{
* Corresponding author

e-mail: galenovatanya@gmail.com
}

life-threatening health complications [3]. Hence, patients with diabetes have to constantly monitor their glycemic status and manage this by utilizing a great arsenal of pharmacological agents. Unfortunately, like all medicines, drugs for diabetes prevention have many adverse effects, and, what is more important, often oral medications independently cannot maintain stable blood glucose level and keep the progression of diabetes under control.

Despite recent advances in anti-diabetic strategies, it is still unknown how to treat diabetes without undesirable side effects. In research and development, developing more effective, safer, and cheaper anti-diabetic drugs remain a formidable challenge.

Plants provide an amazing source of natural remedies for treatment of different diseases. Moreover, secondary metabolites of plant origin serve as an invaluable chemical library for drug discovery and current medicinal chemistry in the pharmaceutical industry. Over the past 25 years, 
$50 \%$ of all prescription drugs have been developed from natural compounds and their derivatives [4]. In recent years, many researchers have focused their attention on the antidiabetic properties of medicinal plants [5-8]. Many phytochemicals from traditional herbs have been identified and purified $[9,10]$. Nowadays, some of them are widely used in clinic as stand-alone agents; others are proposed to use as the structure-base for designing and synthesis of new compounds for diabetes treatment. Herbal pharmaceutical products are considered to have a number of significant advantages in comparison with synthetic medications. Among these are low toxicity and multidirectional therapeutic action [11].

Animal studies have shown that a variety of plant compounds such as peptides (for example S-alilcistein), alkaloids (leurozin, vindolin), cumarin, steroids (fenugrekin), vitamin E, lectins, polysaccharides (acarbose), as well as inorganic ions ( $\mathrm{Cr}, \mathrm{Mn}, \mathrm{Mg})$, might have hypoglycemic effect [12]. The Phaseolus vulgaris plant is a rich source of components that might have beneficial effects in treating diabetes. Among these are trigonelline, arginin, titosin, levicin, lysine, tryptophane, asparagine, chrome, vitamin C, hemicelluloses and soluble fibers $[13,14]$. Moreover, it is known that in the folk medicine of some countries, tea with $P$. vulgaris is widely used as an effective hypoglycemic remedy [15]. But on the other hand, due to the lack of information about the mechanism of its hypoglycemic action and controversial data regarding its antidiabetic effects, the expediency of using this herbal product as a drug in diabetes treatment is not officially confirmed. This study was conducted to investigate the mechanism of hypoglycemic action of $P$. vulgaris pods extract.

\section{MATERIALS AND METHODS}

\section{Plant Material}

The pods of Phaseolus vulgaris L. (white kidney bean) were collected at a field located in Kyiv region, Ukraine in August 2016 and were authenticated by the Department of Botany of Taras Shevchenko National University of Kyiv, Ukraine. The bean pods were separated from seeds, washed with tap water several times, then with distilled water to remove dust and were left to dry at room temperature. The dried bean pods of $P$. vulgaris were then powdered with a manual mill and stored in vacuum packaging at $4{ }^{\circ} \mathrm{C}$ until used.

\section{Preparation of Plant Extract}

A crude extract was prepared by boiling $132 \mathrm{~g}$ of powdered $P$. vulgaris bean pods in 1.0 liter of distilled water for $20 \mathrm{~min}$. After boiling, the extract was left overnight to infuse. In order to remove plant debris, the obtained extract was filtered through cotton wool and then the filtrate was centrifuged at $1000 \mathrm{~g}$ for $10 \mathrm{~min}$. The pure supernatant was frozen and lyophilized to dryness using a freeze-dryer (The Telstar LyoQuest, Spain) at $-56^{\circ} \mathrm{C}$ for $24 \mathrm{~h}$ under pressure of 0.05 mbar. The obtained brown powder $(8 \mathrm{~g})$ was stored at $-20^{\circ} \mathrm{C}$. The fixed dose of aqueous solution of lyophilized extract was given orally using the $16 \mathrm{G}$ oral feeding needle.

\section{Animal housing conditions and Experimental Details}

All animal procedures were in compliance with the European Directive 2010/63/EU (EC, 2010) on the protection of animals used for experimental and other scientific purposes. All manipulations were approved by the Ethical Committee of Educational and Scientific Center "Institute of Biology and Medicine", Taras Shevchenko National University of Kyiv.

Adult male Wistar rats ( $\sim 8$ weeks old) were used in the experiments. They were housed in a temperature-controlled room $\left(22-25^{\circ} \mathrm{C}\right)$ with 12 -h light-dark cycle for at least 1 week to acclimatize. The animals had free access to a commercial pellet diet and water ad libitum.

\section{Induction of diabetes in rats}

Type 1 diabetes mellitus (DM) was induced in the $16 \mathrm{~h}$ fasted rats with a single intraperitoneal injection of $45 \mathrm{mg} \cdot \mathrm{kg}^{-1}$ b.w. streptozotocin (STZ; Sigma, USA) dissolved in $0.5 \mathrm{ml}$ of freshly prepared $0.01 \mathrm{M}$ citrate buffer, pH 4.5 [16]. Control animals received $0.5 \mathrm{ml}$ of vehicle alone. Hyperglycemia was confirmed by measuring glucose $72 \mathrm{~h}$ after the STZ injection and 7 days after injection, confirming a high glucose level. The blood glucose levels in fasting experimental rats were measured with glucometer 'GlucoDrTM.auto' (Allmedicus Co., Ltd, Korea). Rats with permanent high fasting blood glucose level $>15 \mathrm{mmol} \cdot \mathrm{L}^{-1}$ were included for the experiments.

\section{Single-dose studies in diabetic rats}

The experimental animals were fasted for $16 \mathrm{~h}$. Rats of nondiabetic control (Group 1) and diabetic control (Group 2) groups ( $\mathrm{n}=12$ ) were orally administered with water $\left(1 \mathrm{ml} \cdot 100 \mathrm{~g}^{-1}\right.$ b.w.). The extract treated groups $(\mathrm{n}=12)$ of nondiabetic (Group 3), as well as diabetic (Group 4) rats received a single dose of aqueous solution of lyophilised extract ( $200 \mathrm{mg} \cdot \mathrm{kg}^{-1}$ b.w.). Thirty minutes after water/extract administration, half of the rats from each group were taken for performing an oral glucose tolerance test. The others were sacrificed two hours after the treatment, and hemidiaphragm material was quickly taken out to study glucose utilization.

\section{Repeated dose studies in Types 1 diabetic rats}

The untreated groups $(\mathrm{n}=12)$ of nondiabetic (Group 5) and diabetic (Group 6) rats orally received water $\left(1 \mathrm{ml} \cdot 100 \mathrm{~g} \mathrm{~g}^{-1}\right.$ b.w.) once a day for 28 days. Aqueous solution of lyophilised extract (200 mg $\cdot \mathrm{kg}^{-1}$ b.w.) was administered orally once a day to both nondiabetic (Group 7) and diabetic (Group 8) animals for 28 days.

On the $28^{\text {th }}$ day after $16 \mathrm{~h}$ fasting, half of the rats from each group were subjected to the oral glucose tolerance test. The next day, the other $16 \mathrm{~h}$-fasted animals were sacrificed. The blood was obtained for further serum separation and hemidiaphragm material was taken for the performing of the study of glucose utilization. Samples of hind limb muscle tissue were also taken and stored in liquid nitrogen until they were used for biochemical analysis. The pancreases were also collected and stored in $10 \%$ formal saline for later histopathological examination. 


\section{Oral glucose tolerance test (OGTT)}

The blood was sampled from the tail vein, and the glucose levels were checked using the glucometer 'GlucoDr. ${ }^{\mathrm{TM}}$ auto' (Allmedicus Co., Ltd, Korea). Each of the rats was given an oral glucose load of $3 \mathrm{~g} \cdot \mathrm{kg}^{-1}$ b.w. The blood samples were taken before glucose treatment (time 0 ) and every 30 min up to $150 \mathrm{~min}$. Blood glucose concentrations were determined at all time points of OGTT. The glycemic curves were drawn by plotting blood glucose $\left(\mathrm{mmol} \cdot \mathrm{L}^{-1}\right)$ against time $(\mathrm{min})$. The integrated area under the glycemic curve $\left(\mathrm{AUC}_{\text {glucose }}\right)$ was calculated using OriginLab version 93E.

\section{Insulin content measurement}

The insulin concentration was measured in serum by enzyme-linked immunosorbent assay (ELISA), following the standard protocol. Samples of serum were previously diluted 1:10 in Tris-buffered saline (TBS; $50 \mathrm{mM}$ Tris, $137 \mathrm{mM}$ $\mathrm{NaCl}, \mathrm{pH} 7.4)$ and added in $100 \mu 1 /$ well volumes to 96 -well ELISA plates and allowed to adsorb overnight at $4^{\circ} \mathrm{C}$. After incubation, the plates were washed 3 times with TBS, containing $0.05 \%$ Tween 20 , and blocked with $5 \%$ nonfat dry milk for $1 \mathrm{~h}$ at $37^{\circ} \mathrm{C}$. After washing, rabbit polyclonal insulin antibody (Santa Cruz Biotechnology, Inc., USA; product No. sc-9168) was added to the plates, and incubated for an hour at $37^{\circ} \mathrm{C}$. Plates were then washed and incubated for an hour at $37^{\circ} \mathrm{C}$ with anti-rabbit antibody conjugated to horseradish peroxidase (Sigma-Aldrich, USA; product No. A8275). After washing, chromogenic substrate o-phenylenediamine (Sigma-Aldrich, USA; Product No. P 9029), $0.4 \mathrm{mg} / \mathrm{ml}$ in $0.05 \mathrm{M}$ phosphate-citrate buffer, $\mathrm{pH} 5.0$ containing hydrogen peroxide was added. The reaction was stopped by the addition of $2.5 \mathrm{~N} \mathrm{H}_{2} \mathrm{SO}_{4}$. The plates were read at $492 \mathrm{~nm}$ by a microplate reader - mQuantTM (BioTek Instruments, Inc., USA).

\section{Glucose utilization by isolated rat hemidiaphragm}

The glucose utilization by isolated rat hemidiaphragm was determined according to published procedures [17]. Diaphragms from experimental rats were taken out quickly to avoid the bleeding which results from puncturing the posterior vena cava of the liver. The isolated diaphragms were immediately placed in cold Kreb's-Henseleit bicarbonate buffer (KHB; $119 \mathrm{mM} \mathrm{NaCl}, 4,7 \mathrm{mM} \mathrm{KCl}, 2.0 \mathrm{mM}$ $\mathrm{KH}_{2} \mathrm{PO}_{4}, 25 \mathrm{mM} \mathrm{NaHCO}_{3}$, and $2.5 \mathrm{mM} \mathrm{CaCl}_{2}$ ). Each diaphragm was cleaned of fat, connective tissue and extremely thin muscle at the periphery, and subsequently cut into two pieces before being weighed. Each muscle segment was then soaked at $4^{\circ}$ for $15 \mathrm{~min}$ in $5 \mathrm{~mL}$ of KHB solution contained $6 \mathrm{mM}$ glucose. Each hemidiaphragm was then transferred to another tube containing $2,5 \mathrm{~mL}$ of KHB solution with $6 \mathrm{mM}$ glucose for measurement of the glucose uptake. The test tubes with hemidiaphragms were placed in a water bath at $37^{\circ}$ and were shaken at 130 cycles per minute for 2 hours. At the end of the 2 hour period, the tubes were placed in ice water. The glucose concentration in the medium was measured at the start $(0 \mathrm{~h})$ and after the incubation $(2 \mathrm{~h})$ by the glucose oxidase method, using a commercial kit (Filisit Dignostic, Ukraine). All manipulations were carried out according to the manufacture's instructions provided in the kit. The glucose uptake was calculated as the difference between the initial ( $0 \mathrm{~h}$ point) and the final ( $2 \mathrm{~h}$ point) glucose concentration in the incubation medium. The results were presented as mmol of glucose per $\mathrm{g}$ of tissue.

\section{Membrane fraction separation}

The frozen muscle tissue samples were homogenized in ice-cold $5 \times$ volume of homogenization buffer, $\mathrm{pH} 7.5$ (20 mM Tris- $\mathrm{HCl}, 0.25 \mathrm{M}$ sucrose, $10 \mathrm{mM}$ EGTA, $2 \mathrm{mM}$ EDTA, $2 \mathrm{mM} \mathrm{Na}_{3} \mathrm{VO}_{4}, 1 \mathrm{mM}$ phenylmethylsulfonyl fluoride, $2 \mathrm{mM}$ dithiothreitol). The homogenate was firstly centrifuged at $800 \mathrm{~g}$ for $15 \mathrm{~min}$ and then at $15000 \mathrm{~g}$ for $30 \mathrm{~min}$ to obtain a post mitochondrial fraction. The supernatant was then centrifuged at $40000 \mathrm{~g}$ for $40 \mathrm{~min}$. The obtained pellet (membrane fraction) was solubilized 1:1 in lysis buffer, pH 7.4 (50 mM HEPES, 1\% Triton X-100, 10\% glycerol, $1 \mathrm{mM} \mathrm{DTT}, 1 \mathrm{mM} \mathrm{Na}_{3} \mathrm{VO}_{4}$ ) for $15 \mathrm{~min}$ at $4{ }^{\circ} \mathrm{C}$. Then lysate was centrifuged at $40000 \mathrm{~g}$ for $30 \mathrm{~min}$. The pure supernatant that represents the solubilized membrane proteins was collected and used for the analysis of the content of insulin receptor and the glucose transporter, and the total tyrosine protein kinase activity as well.

\section{Insulin receptor and glucose transporter analysis}

To observe the effects of the extract on the content of insulin receptor (IR) and glucose transporter (GLUT-4) in skeletal muscle tissue, ELISA techniques were carried out. ELISA plates were coated overnight at $4{ }^{\circ} \mathrm{C}$ with samples of muscle solubilized membrane fraction previously diluted with TBS, pH 7.4 to obtain concentration of proteins $10 \mu \mathrm{g} \cdot \mathrm{mL}^{-1}$. After being washed, plates were blocked with $5 \%$ nonfat dry milk for $1 \mathrm{~h}$ at $37^{\circ} \mathrm{C}$ and then washed again. After that plates were incubated for $1 \mathrm{~h}$ at $37^{\circ} \mathrm{C}$ with specific rabbit polyclonal anti-GLUT-4 antibody (Millipore, USA; product No. 07-1404) or mouse monoclonal anti-insulin receptor antibody (Millipore, USA; product No. 05-1104). Plates were washed and incubated for $1 \mathrm{~h}$ at $37^{\circ} \mathrm{C}$ with corresponding secondary antibodies conjugated to horseradish peroxidase (Bio-Rad, USA). After washing, the substrate $o$-phenylenediamine/hydrogen peroxide (Sigma, USA) was added. The reaction was stopped by addition of $2.5 \mathrm{~N} \mathrm{H}_{2} \mathrm{SO}_{4}$. The plates were read at $492 \mathrm{~nm}$ by a microplate reader mQuant ${ }^{\mathrm{TM}}$ (BioTek Instruments, Inc). The IR and GLUT-4 concentration in the control group of animals (Group 1) was set at $100 \%$ and changes in protein concentration were given as percentage of controls.

\section{Analysis of tyrosine protein kinase (TPKase) activity}

The kinase assay was performed according to published procedures [18]. The reaction was carried out in 96-well plates precoated with polyGlu/Tyr substrate (Sigma, USA; product No. P7744) at pH 7.4 in a reaction medium (final volume was $100 \mu \mathrm{l}$ ) that consisted of $50 \mathrm{mM}$ HEPES, $20 \mathrm{mM} \mathrm{MgCl}, 0.1 \mathrm{mM} \mathrm{MnCl}_{2}, 0.2 \mathrm{mM} \mathrm{Na}_{3} \mathrm{VO}_{4}$ and $35 \mathrm{nM}$ ATP. The process of phosphorylation was initiated by addition of equal amounts of soluble proteins $(20 \mu \mathrm{g}$ per well). After a $30 \mathrm{~min}$ incubation period $\left(\right.$ at $37^{\circ} \mathrm{C}$ ), the phosphorylated tyrosine residue in polyGlu/Tyr substrate was measured via ELISA. In brief, after incubation, the wells were washed 3 times with TBS containing $0.05 \%$ Tween 20 . 
Next, the HRP-conjugated anti-phosphotyrosine antibody (Sigma, USA; product No. 16-454) was added to the wells and incubated for $1 \mathrm{~h}$ at $37^{\circ} \mathrm{C}$. The wells were washed again and then incubated with the peroxidase substrate o-phenylenediamine/ hydrogen peroxide (Sigma, USA). The reaction was stopped by the addition of $2.5 \mathrm{~N} \mathrm{H}_{2} \mathrm{SO}_{4}$ and the degree of tyrosine phosphorylation was quantified by reading the optical density at $492 \mathrm{~nm}$ by means of a microplate reader - mQuant ${ }^{\mathrm{TM}}$ (BioTek Instruments, Inc).

\section{Histopathological studies}

The pancreases were fixed in $10 \%$ formalin solution that contains $4 \%$ (wt/vol) formaldehyde. After fixation, the samples were dehydrated and embedded in paraffin. After this, sections of $5 \mu \mathrm{m}$-thick were cut using a microtome Microm HM325. The sections of pancreas were deparaffinized in xylene, hydrated in decreasing concentrations of ethanol, stained with hematoxyline and eosine, dehydrated, cleaned up, and mounted with mounting medium. The analysis for any histopathological changes was carried out using a microscope Olympus BX41 at magnification $\times 400$. The digital microphotographs of the stained sections of pancreases were taken using a computer-assisted image analyzing system (microscope Olympus BX41 and Olympus digital camera C5050).

\section{Statistical analysis}

The statistical analysis was performed using StatSoft Statistica version 7.0 for Windows. All data in this study were expressed as mean \pm standard deviation $(\mathrm{M} \pm \mathrm{SD})$ or percentage with $n=10$. Statistical significance was tested by one-way analysis of variance (ANOVA), followed by Tukey's multiple comparison test. The differences were considered to be statistically significant when $\mathrm{p}$-value were less than 0.05 .

\section{RESULTS}

\section{Oral glucose tolerance test (OGTT)}

The results of the glucose tolerance test in control and diabetic rats in case of both single-dose and repeated dose studies are shown in Figure 1 (A and B, respectively).

We observed that after single and repeated administration to the control rats, $P$. vulgaris aqueous extract showed significant antihyperglycemic effects. Furthermore, single extract treatment reduced the blood glucose levels in control rats (Group 3) at the 60-min time point, compared with the Group 1 (Fig. 1A). Moreover, the blood glucose concentration remained at the low level until the end of the monitoring period. In case of the repeated dose study, the treatment of control rats (Group 7) with P. vulgaris extract resulted in suppression of glucose levels in OGTT even more effectively then after single dose. The AUC data (Fig. 1C) confirmed the trends of lowering of the glucose levels in the result of $P$. vulgaris extract treatment. In rats of Group 3, the AUC value was reduced by $15 \%$, whereas after a 28 -day extract administration in rats of Group 7, this parameter was
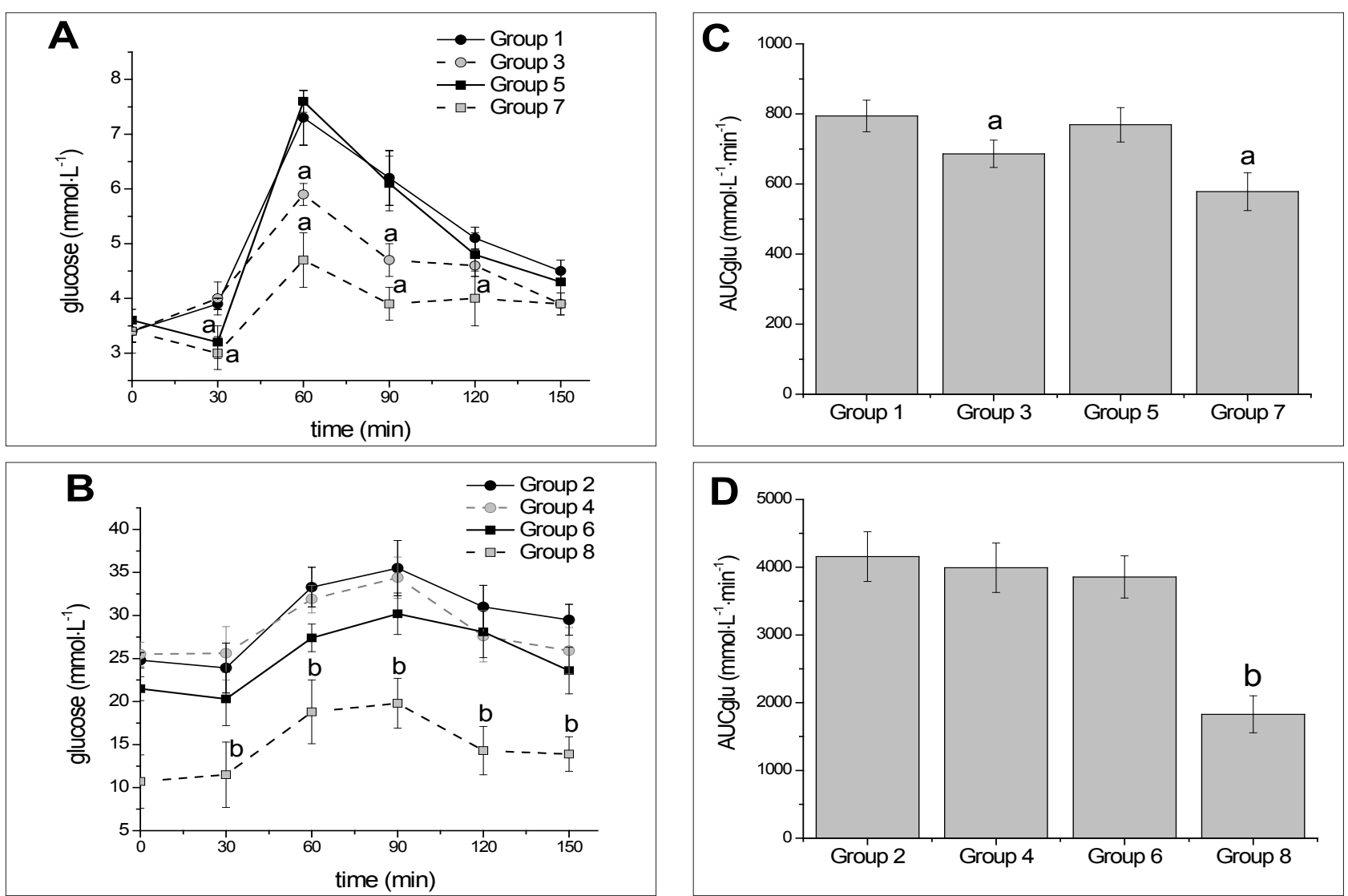

Different letters indicate significant differences: ${ }^{\mathrm{p}} \mathrm{p}<0.05$; ${ }^{\mathrm{b}} \mathrm{p}<0.01$; when compared with corresponding untreated group of control (group 1 ) or diabetic (group 2 ) rats

Figure 1. Oral glucose tolerance test results after single or repeated administration of $P$. vulgaris pod extract: blood glucose levels in control (A) and diabetic (B) rats; AUC values of control (C) and diabetic (D) rats 
decreased by $30 \%$, compared with the values of Group 1 and 5, respectively (Fig. 1C).

The single $P$. vulgaris extract administration to diabetic rats (Group 4) did not have influence on the blood glucose levels in the OGTT (Fig. 1B) and the AUC index did not differ from the index of water-treated diabetic rats of the Group 2 (see Fig. 1D). But 28-day treatment of diabetic rats (Group 8) resulted in a significant reduction of glucose levels in the OGTT (Fig. 1B), compared with the Group 6. Moreover, the AUC data also indicated a trend of suppression in glucose levels of 2.1 times as the result of extract treatment (Fig. 1D). In addition to this, repeated dose treatment of diabetic rats with $P$. vulgaris extract had affect on the fasted blood glucose level and lowered it in 2 times compared with the level of the water-treated diabetic rats (Group 6) (Fig. 1B).

\section{Glucose utilization}

To examine whether $P$. vulgaris extract activates glucose utilization by peripheral tissues, diaphragms from the experimental rats were isolated and in vitro measurement of glucose uptake in muscle cells was cared out. The hemidiaphragms were placed in a medium containing $6 \mathrm{mM}$ glucose and incubated at $37^{\circ} \mathrm{C}$ for $2 \mathrm{~h}$. The levels of glucose in the medium were measured at the start and after the $2 \mathrm{~h}$ incubation. The results of the experiment are expressed in the Figure 2.
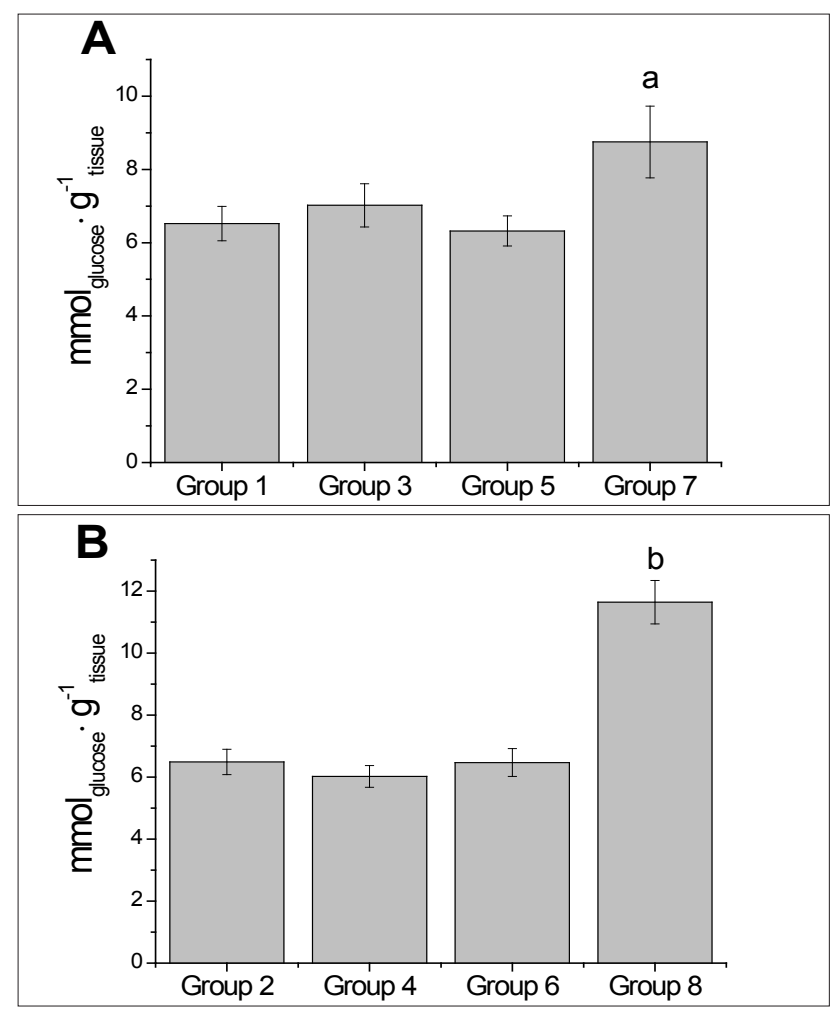

Different letters indicate significant differences: ap $<0.05$; ${ }^{b} p<0.01$; when compared with corresponding untreated group of control (group 1 ) or diabetic (group 2) rats

Figure 2. The effect of $P$. vulgaris pods extract on glucose utilization by the diaphragmatic tissue of control (A) and diabetic (B) rats in the case of both single-dose (Groups 3 and 4) and repeated dose (Groups 7 and 8) studies
As we can conclude from the obtained data, a single oral administration of $P$. vulgaris extract to either control or diabetic rats (Group 3 and 4, respectively) did not influence on the levels of muscle cells glucose uptake (Fig. 2A and B). Noteworthy is that long-term extract introduction to control rats (Group 7) showed a marked increase of glucose utilization (by 30\%), compared with the water-treated control (Group 5) (Fig. 2A). The same trend was observed in diabetic rats after 28-day treatment with extract. The level of glucose utilization in muscle cells of the Group 8 animals was $80 \%$ higher, compared with water-treated diabetic rats (Fig. 2B).

Since a single oral administration of $P$. vulgaris extract did not show visible antihyperglycemic effect in diabetic rats and did not have influence on the rate of glucose utilization by muscle cells of both control and diabetic rats, while in the case of repeated-dose studies, the $P$. vulgaris extract showed better efficacy to maintain glucose level in the OGTT test and to increase the rate of glucose in-take by the cells of hemidiaphragms of diabetic and control rats, all further experiments were focused on the evaluation of biochemical parameters of control and diabetic rats after the 28-day treatment period (experimental groups of rats from 5 to 8 ).

\section{Insulin study}

The serum insulin level was measured after long-term treatment of control and diabetic rats with $P$. vulgaris extract (Fig. 3). Results of this revealed that in both diabetic groups - water-treated (Group 6) and treated with extract (Group 8), the levels of serum insulin were decreased by $25-35 \%$ compared with corresponding control. Control rats which received $P$. vulgaris extract (Group 7) did not show the difference in insulin level, compared with the group of watertreated control (Group 5). Based on the obtained results, we concluded that treatment of rats with extract had no effect on the serum insulin level.

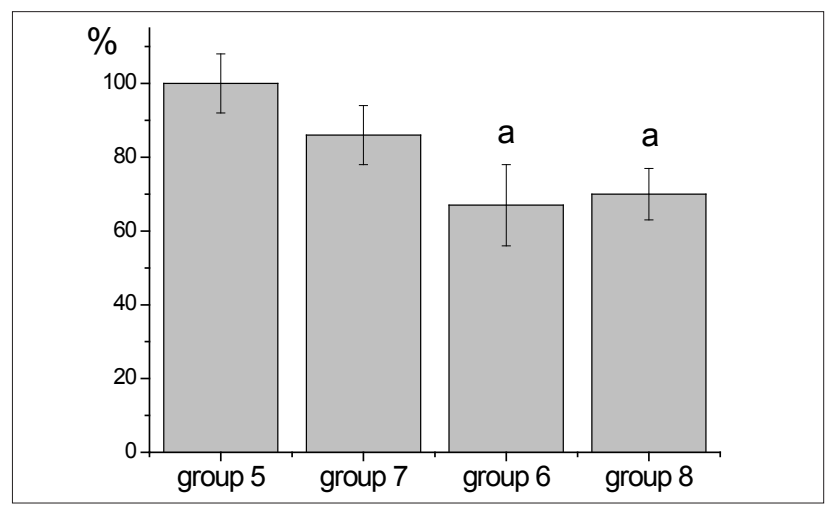

${ }^{a} \mathrm{p}<0.05$ when compared with long-term water-treated control rats (group 5) Figure 3. The serum insulin levels in control and diabetic rats after 28-day treatment with $P$. vulgaris extract

\section{Histopathological studies}

From the results of histopathological studies, it was clear that the pancreatic tissues of animals from the both control groups - the water-treated and the treated with extract (Group 5 and 7, respectively) had normal distribution of islets of Langerhans with well-defined boundaries (Fig. 4A and B). 
Herein, the exocrine part of the glands is represented by the closely packed pancreatic acini with narrow lumen and with thin connective septa between them. The ducts were present between acinar cells. Each acinar cell had a bright manifestation of basophilia on the basal and acidophilia on the apical side. The nucleus typically was rounded or oval and occupied the basal part of the cells. The center of the acini was occupied by small centroacinar cells that showed an oval euchromatin-containing nuclei and less eosinophilic cytoplasm (Fig. 4A and B).

We noted that the pancreas of diabetic rats (Group 6) showed reduction of the pancreatic islets in size (Fig. 4C). This maybe due to the $\beta$-cell destruction caused by necrosis and was reflected in the decrease in cell density. The betacells looked enlarged with weak acidophilic level of cytoplasm staining and were often vacuolated. This effect results in less insulin content. Moreover, individual cells underwent dystrophic changes (Fig. 4C).

In the diabetic rats treated with extract (Group 8), the pancreas did not undergo such pathological changes as seen in the water-treated diabetic animals (Group 6). The amount and structure of islets were found to be rather normal. The Langerhans' islands were not diminished in size and dystrophically altered cells were not detected. However, there were a weak vacuolization of the cytoplasm in some cells. Vacuolation of the acinar cells was more visualized compared with Group 5, but significant less than in the Group 7 (Fig. 4D).
Tyrosine protein kinase activity and insulin receptor content in membrane of skeletal muscle cells

In the group of water-treated diabetic rats (Group 6), total TPKase activity in membrane of skeletal muscle cells was lower by 2.6 times compared with Group 5 (water-treated control rats) (Fig. 5A).

We saw that in the control and the diabetic groups of animals that, during 28 days, received $P$. vulgaris extract, the total membrane TPKase activity of skeletal muscle cells was significantly reduced (Fig. 5A): in the Group 6, by 2.2 times, and in Group 8, by 3 times, compared to the group of water-treated control (Group 5).

The study of the total IR content in membrane of skeletal muscle cells indicated that this parameter did not differ among all experimental groups - neither untreated nor treated with $P$. vulgaris extract for 28 days (Fig. 5B).

\section{Total Glucose Transporter Content in skeletal muscle cells}

As expected, the total GLUT-4 content in skeletal muscle cells of the diabetic water-treated rats (Group 6) was significantly reduced (by $25 \%$ ) compared to this parameter of the nondiabetic control rats (Group 5). P. vulgaris extract treatment showed a trend towards an increase in the GLUT-4 content in skeletal muscle cells of both nondiabetic and diabetic rats (Fig. 6). In the group of control rats
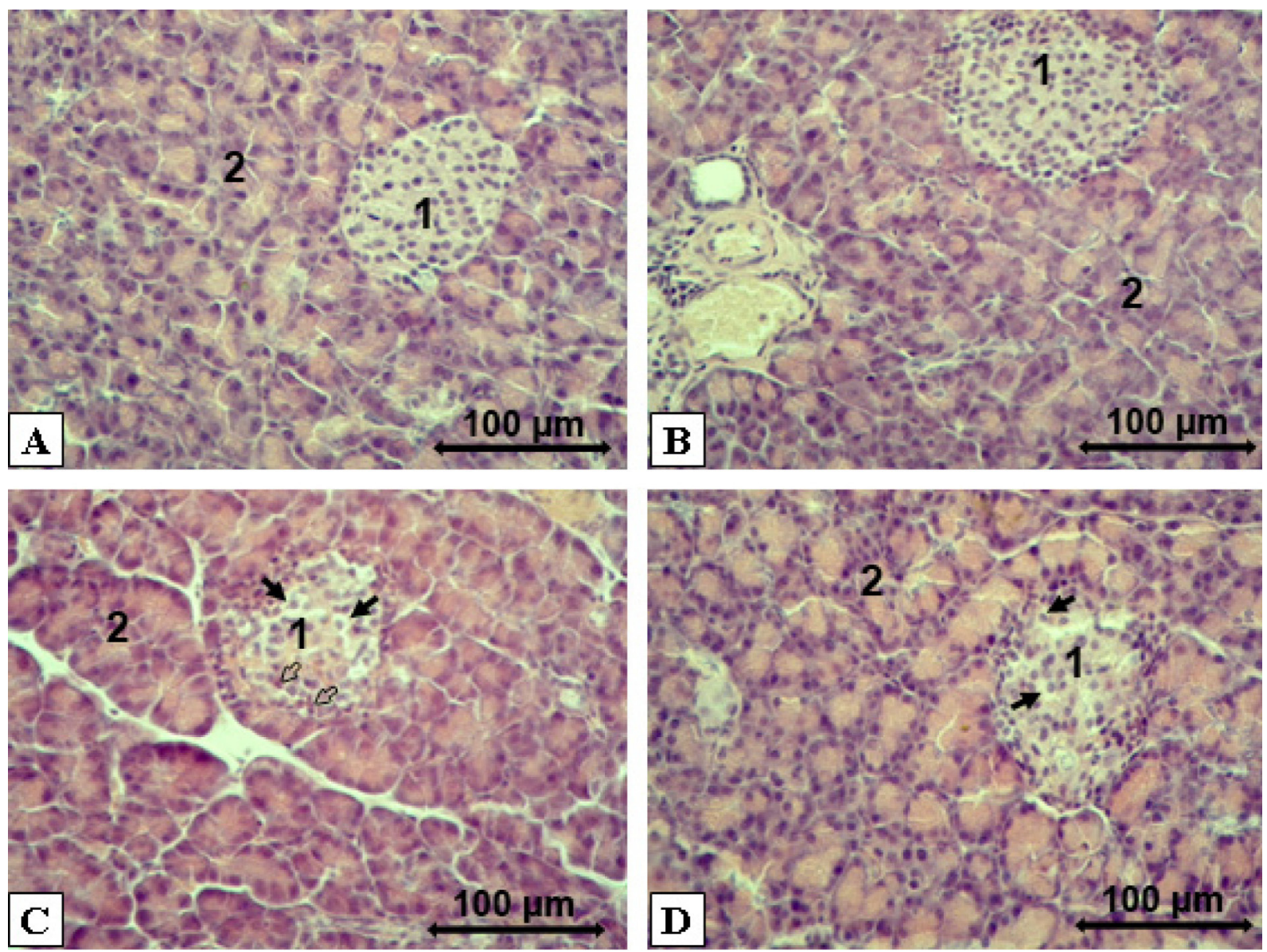

1 - islets of Langerhans, 2 - acinar cells of the exocrine part of gland, black arrows - vacuolization of the cytoplasm, white arrows - destruction of the $\beta$-cells Figure 4. Histopathological changes in rat's pancreas (H\&E staining; magnification $\times 400)$ in water-treated $(\mathbf{A})$ and $P$. vulgaris extracttreated (B) control groups and in water-treated (C) and P. vulgaris extract-treated (D) diabetic groups 

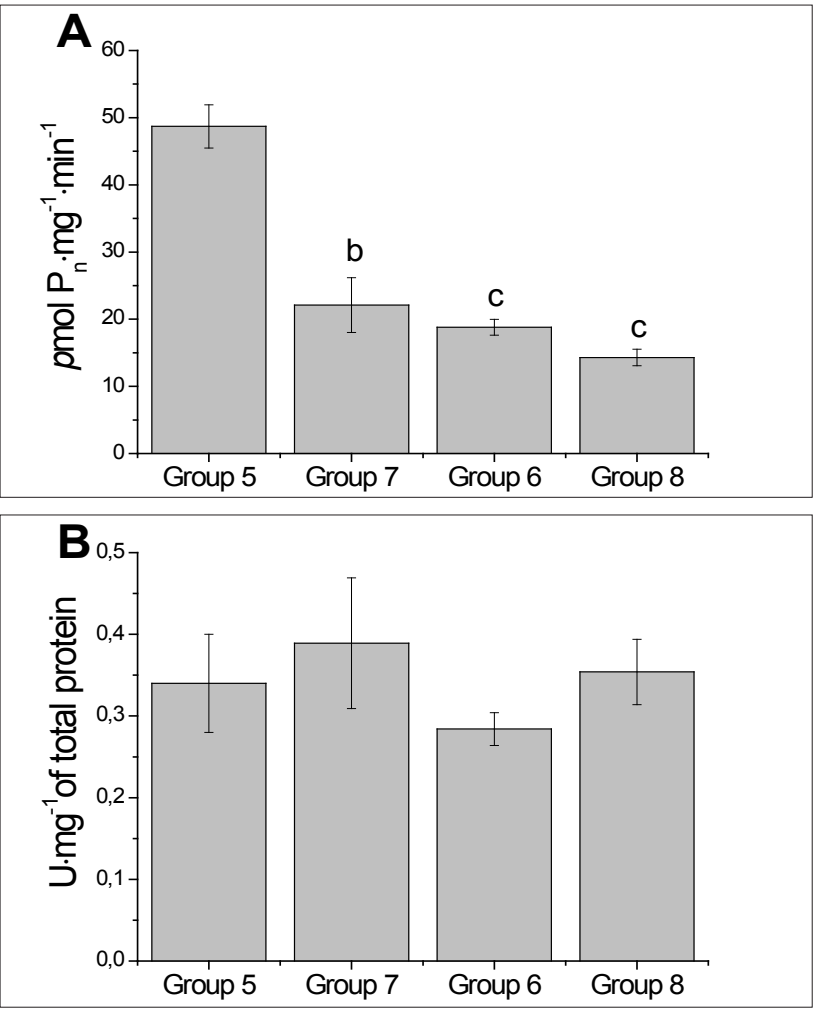

Different letters indicate significant differences: ${ }^{b} p<0.01$; ${ }^{c} p<0.001$; when compared with long-term water-treated control rats (group 5)

Figure 5. The total membrane TPKase activity (A) and the total insulin receptor content (B) in skeletal muscle cells of control and diabetic rats after 28-day treatment with $P$. vulgaris extract

administered with extract (Group 7), the GLUT-4 content was elevated by $20 \%$ compared with that of Group 5 . In Group 8, this parameter was increased by $50 \%$ compared to the same parameter of the water-treated diabetic animals. Moreover, no significant difference was seen between the total muscle GLUT-4 content of rats from the water-treated control group and the group of diabetic rats after 28-day extract treatment (Fig. 6).

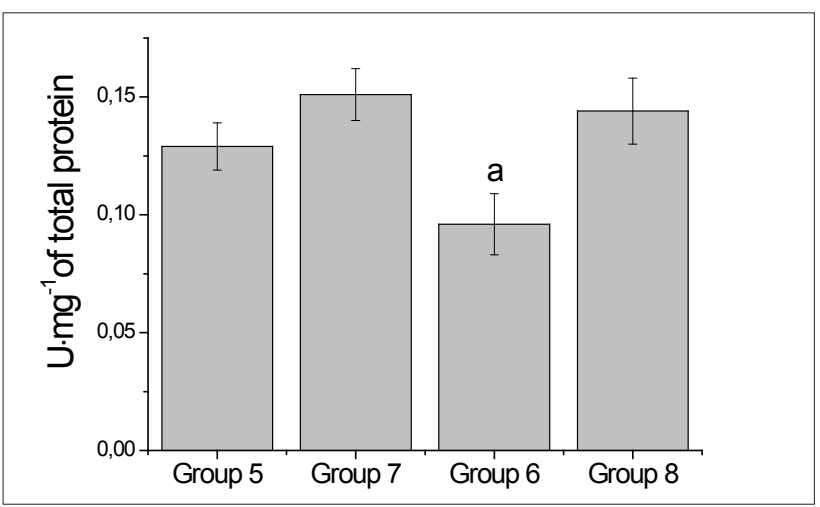

ap $<0.05$ when compared with long-term water-treated control rats (group 5) Figure 6. Total GLUT-4 content in skeletal muscle cells of control and diabetic rats after 28-day treatment with $P$. vulgaris extract

\section{DISCUSSION}

Phaseolus vulgaris is widely cultivated for its delicious seeds that add flavor and protein to the diets of millions of people throughout the world. In addition to this, $P$. vulgaris plays an important role in folk medicine; it has been used as a diuretic and hypotensive agent. Current studies have also demonstrated that a repeated administration of $P$. vulgaris extracts, as well as of some of their isolated ingredients, reduced the food intake, body weight and lipid accumulation in lean and obese laboratory animals [19].

The fruit walls of $P$. vulgaris bean pods, that are free from the seeds, are also widely used all over the world as a decoction with hypoglycemic properties. At the first time, in a 1991 study, an aqueous extract of $P$. vulgaris bean pods were found to have an antihyperglycemic effect [20]. This was confirmed in 1995 [21]. Since then, scientific interest in the antidiabetic potential of bean pods has never vanished completely and has been enhanced over the past decades. In 2003, the glucose lowering effects of a hot aqueous extract prepared from $P$. vulgaris pods $(200 \mathrm{mg} / \mathrm{kg})$ on streptozotocin diabetic rats was confirmed [22, 23]. Later, it was also made mention that such extracts induced a decrease in blood glucose levels that was accompanied by an increase in insulin levels [24]. Some controversial results have been reported as well: no effects of an aqueous extract (prepared from $15 \mathrm{~g}$ of powdered pods in $300 \mathrm{ml}$ of water), given in a dose of $25 \mathrm{~g}$ of extract $/ \mathrm{kg}$, on streptozotocin diabetic mice were reported in an oral glucose tolerance test [25], and no positive effects on glucose tolerance in the case of a healthy volunteer treatment was indicated [26].

Previously, we have reported that an extract of $P$. vulgaris $(200 \mathrm{mg} / \mathrm{kg}$ ) has a marked hypoglycemic effect and positive influence on carbohydrate and lipid metabolism, antioxidant system and immune status in a model of streptozotocininduced diabetes in rats [27-29]. Currently, the data on mechanism of antidiabetic action and bioactive constituent of $P$. vulgaris bean pods are limited in literature. There are hardly any scientific reports studying the effects of bean pod extract on glucose metabolism. In this work, we have explored whether the extracts of $P$. vulgaris could reduce glucose levels in an animal model of diabetes and which mechanism could be involved in realization of the hypoglycemic action.

Building on an experimental model of streptozotocinindused diabetes, we confirmed that $P$. vulgaris has strong antyhyperglicemic properties. Herein, the antihyperglycemic effect of $P$. vulgaris extract, after a single administration to control rats, may be due to the increased release of insulin from the $\beta$-cells of pancreas [30]. The mechanism of influence of $P$. vulgaris on islet cells is not well-understood, but this effect of $P$. vulgaris was shown in previous studies.

As expected, after streptozotocin injection, the rats showed elevated blood glucose level and markedly reduced level of serum insulin. In this regard, the diabetogenic agent streptozotocin causes a state of insulin-dependent diabetes mellitus through its ability to induce a selective necrosis of the pancreatic beta cells [31]. In our experiments, the destruction of islets of Langerhan was confirmed by the results of histological examination. The presented results indicated that the pancreas was at least partially deteriorated by STZ injection and it seems expected that damaged $\beta$ cells were unable to produce a sufficient amount of endogenous insulin to keep a physiological level of glucose.

According to the obtained data, the single-dose administration of $P$. vulgaris extract to diabetic rats had no effect on 
fasting blood glucose level or glucose dynamic in OGTT. In contrast, in the repeated-dose study, a significant decrease of fasting hyperglycemia was observed. Moreover, in the glucose tolerance test in diabetic rats after the repeateddose treatment, the area under the glucose tolerance curve was markedly reduced. In contrast with improvement of glycemic control, daily oral administration of the aqueous extract of $P$. vulgaris to diabetic rats for 28 days did not produced an insulinotropic effect. Still, the extract-treated diabetic rats showed a significant decrease of the serum insulin level compared with the water-treated control group. Although, the serum insulin level in the extract-treated diabetic rats was at the same low level as in water-treated diabetic rats, some beneficial effects of extract on pancreas structure were observed. This suggest that the extract might partially rescue the rats' exhausted pancreatic $\beta$-cells from further damage that usually associated with prolonged high glucose level. It is well known that chronic hyperglycemia leads to the auto-oxidation of glucose and causes the nonenzymatic glycation of proteins through Maillard's reaction which produces Schiff base, Amadori product, and finally advanced glycation end products [32] which might deteriorate the function of pancreatic beta cells.

Since the antihyperglycemic effect of $P$. vulgaris in our experiment might not be due to its ability to stimulate pancreatic $\beta$-cells to secrete more insulin, we hypothesize that the decrease of hyperglycemic level and the increase of glucose tolerance in OGGT might be through its positive influence on the process of glucose utilization and metabolism.

In literature, beyond the beneficial effect on insulin secretion, one more possible mechanism of $P$. vulgaris effects on glycemia is discussed. This is focused on the role of the $\alpha$-amylase inhibitors and phytohemagglutinin that are present in different parts of this plant. Since the pancreatic $\alpha$-amylase catalyzes the hydrolysis of $\alpha$ - $(1,4)$-glycosidic bonds of starch polymers, the inhibition of this enzyme results in the suppression of starch metabolism and, in turn, to the decrease in glycemia [33]. Phytohemagglutinin is known to bind to the stomach epithelial cells and to the brush border membrane of the small intestine that results in the stimulation of the release of cholecystokinin and glucagon like peptides [34] - two hormones that play a substantial role in digestive processes. Based on the evidence of the presence of $\alpha$-amylase inhibitors and phytohemagglutinin in the $P$. vulgaris extract, we could explain that hypoglycemic effect that we observed in experimental rats is due to the aforementioned. However, taking into account the results of glucose uptake studies, we think the observed effect might be due to the additional mechanism of the lowering of glucose concentration in response to the $P$. vulgaris extract treatment.

The significant finding of this work is that the extract of $P$. vulgaris possesses considerable insulin-like properties. The evidence of this is in the enhancement of glucose uptake in the diaphragm, which represents muscle cells that are the major site of insulin-stimulated glucose disposal. We have examined the potential mechanism underlying the improvement in glucose utilization by the extract. The results showed that the extract-treated diabetic rats had significantly increased GLUT4 content compared with the value of the water-treated diabetic rats, which resulted in resettled glucose transporter content to the control level. However, the insulin receptor content remains at the basal level and the tyrosine kinase activity was significant lower than in animals without treatment. We conclude, hence, that the extract of $P$. vulgaris has activated the transcription of GLUT-4 and has had influence on its intracellular translocation. Still, another insulin-stimulated pathway may be involved in the regulation of GLUT-4 expression and translocation, which will the subject of further study.

\section{CONCLUSIONS}

Our results provide confirmation that the extract of the fruit walls of $P$. vulgaris pods has strong antidiabetic activity. In this study, we have examined one of the possible mechanisms of antidiabetic properties of the extract. We have shown that the extract may stimulate glucose transport due to the increase of glucose transporter content acting through a mechanism that does not involve the insulin signaling cascade. The signaling mechanisms, as well as the molecules that are responsible for the action of $P$. vulgaris extract remain to be identified.

\section{ACKNOWLEDGEMENTS}

This research did not receive any specific grant from funding agencies in the public, commercial, or not-for-profit sectors.

\section{CONFLICT OF INTEREST}

The authors declare that they have no conflict of interest.

\section{ORCID iDs}

Tetiana Halenova (Dhttps://orcid.org/0000-0003-2973-2646

Natalia Raksha (Dhttps://orcid.org/0000-0001-6654-771X

Olha Kravchenko Dhttps://orcid.org/0000-0003-3817-6485

Tetiana Vovk (1)https://orcid.org/0000-0001-6551-4211

Alona Yurchenko (Dhttps://orcid.org/0000-0001-7148-0644

Igor Vareniuk (Dhttps://orcid.org/0000-0002-9881-5536

Olexii Savchuk (1)https://orcid.org/0000-0003-3621-6981

Ludmila Ostapchenko (Dhttps://orcid.org/0000-0001-7181-6048

\section{REFERENCES}

1. IDF Diabetes Atlas 7th Edition 2015. Available: https://www.idf. org/e-library/epidemiology-research/diabetes-atlas/13-diabetesatlas-seventh-edition.html

2. Blair M. Diabetes Mellitus Review. Urol Nurs. 2016;36(1):27-36

3. Brealey D, Singer M. Hyperglycemia in critical illness: a review. J Diabetes Sci Technol. 2009;3(6):1250-60.

4. Dias DA, Urban S, Roessner U. A Historical Overview of Natural Products in Drug Discovery. Metabolites. 2012;2(2):303-36.

5. Chang CL, Chen YC, Chen HM, et al. Natural cures for type 1 diabetes: a review of phytochemicals, biological actions, and clinical potential. Curr Med Chem. 2013;20(7):899-907.

6. Yeh GY, Eisenberg DM, Kaptchuk TJ, et al. Systematic review of herbs and dietary supplements for glycemic control in diabetes. Diabetes Care. 2003;26(4):1277-94.

7. Covington MB. Traditional Chinese medicine in the treatment of diabetes. Diabetes Spectr. 2001;14:154-9. 
8. Ota A, Ulrih NP. An overview of herbal products and secondary metabolites used for management of type two diabetes. Front Pharmacol. 2017;8:436.

9. Pandey VN, Rajagopalan SS, Chowdhary DP. An effective Ayurvedic hypoglycemic formulation. J Res Ayurveda Siddha. 1995;1-14.

10. Oubre AY, Carlson TJ, King SR, et al. From plant to patient: an ethnomedical approach to the identification of new drugs for the treatment of NIDDM. Diabetologia. 1997;40:614-17.

11. Karimi A, Majlesi M, Rafieian-Kopaei M. Herbal versus synthetic drugs; beliefs and facts. J Nephropharmacol. 2015;4(1):27-30.

12. Bharti SK, Krishnan S, Kumar A, et al. Antidiabetic phytoconstituents and their mode of action on metabolic pathways. Ther Adv Endocrinol Metab. 2018;9(3):81-100.

13. Chávez-Mendoza C, Sánchez E. Bioactive compounds from Mexican varieties of the Common Bean (Phaseolus vulgaris): implications for health. Molecules. 2017;22(8),1360.

14. Reynoso-Camacho R., Ramos-Gomez M., Loarca-Pina G. Bioactive components in common beans (Phaseolus vulgaris L.). Research Signpost. 2006;37/661(2):217-36.

15. Helmstädter A. Beans and diabetes: Phaseolus vulgaris preparations as antihyperglycemic agents. J Med Food. 2010;13(2):251-4.

16. Zafar M, Naqvi S. Effects of STZ-induced diabetes on the relative weights of kidney, liver and pancreas in Albino rats: A comparative study. Int J Morphol. 2010;28(1):135-42.

17. Sabu MC, Subburaju T. Effect of Cassia auriculata Linn. on serum glucose level, glucose utilization by isolated rat hemidiaphragm. J Ethnopharmacol. 2002;80:203-6.

18. Stasevych M, Zvarych V, Lunin V, et al. Novel anthraquinone-based derivatives as potent inhibitors for receptor tyrosine kinases. Indian J Pharm Sci. 2015;77(5):634-7.

19. Carai MAM, Fantini N, Loi B, et al. Potential efficacy of preparations derived from Phaseolus vulgaris in the control of appetite, energy intake, and carbohydrate metabolism. Diabetes Metab Syndr Obes. 2009;2:145-53.

20. Roman-Ramos R, Flores-Saenz JL, Partida-Hernandez G, et al. Experimental study of the hypoglycemic effect of some edible plants. Arch Invest Med (Mex). 1991;22:87-93.

21. Roman-Ramos R, Flores-Saenz JL, Alarcon-Aguilar F. Antihyperglycemic effect of some edible plants. J Ethnopharmacol. 1995;48:25-32.

22. Pari L, Venkateswaran S. Effect of an aqueous extract of Phaseolus vulgaris on plasma insulin and hepatic key enzymes of glucose metabolism in experimental diabetes. Pharmazie. 2003;58:916-9.
23. Almuaigela MF, Seifb MA, Albualia HW, Alharbia O, Alhawasha A. Hypoglycemic and hypolipidemic effects of aqueous extract of phaseolus vulgaris pods in streptozotocin-diabetic rats. Biomedicine \& Pharmacotherapy. 2017; 94:742-6.

24. Pari L, Venkateswaran S. Protective role of Phaseolus vulgaris on changes in the fatty acid composition in experimental diabetes. J Med Food. 2004;7(2):204-9.

25. Neef H, Declercq P, Laekeman G. Hypoglycemic activity of selected European plants. Phytother Res. 1995;9:45-8.

26. Cerovic A, Miletic I, Konic.-Ristic A, et al. The dry plant extract of common bean seed (Phaseoli vulgari pericarpium) does not have an affect on postprandial glycemia in healthy human subject. Bosn J Basic Med Sci. 2006;6(3):28-33.

27. Kyznetsova MY, Lavrovska DO, Zhyvolozhnyi AY, et al. Effect of aqueous extract from Phaseolus vulgaris pods on cytokine profile of streptozotocin-induced diabetic rats. RJPBCS. 2015;6(1):1511-20.

28. Kyznietsova MY, Halenova TI, Savchuk OM, et al. Carbohydrate metabolism in type 1 diabetic rats under the conditions of the kidney bean pods aqueous extract application. Fiziol Zh. 2015;61(6):96-103.

29. Kyznetsova M, Makieieva O, Lavrovska D, et al. Aqueous extract from Phaseolus vulgaris pods on lipid peroxidation and antioxidant enzymes activity in the liver and kidney of diabetic rats. J Appl Pharm Sci. 2015; 5(5):001-6.

30. Oseguera Toledo ME, Gonzalez de Mejia E, Sivaguru M, et al. Common bean (Phaseolus vulgaris L.) protein-derived peptides increased insulin secretion, inhibited lipid accumulation, increased glucose uptake and reduced the phosphatase and tensin homologue activation in vitro. J Funct Foods. 2016; 27:160-77.

31. Lenzen S. The mechanisms of alloxan- and streptozotocin-induced diabetes. Diabetologia. 2008;51(2):216-26.

32. Lim M, Park L, Shin G, Hong H, Kang I, Park Y. Induction of apoptosis of Beta cells of the pancreas by advanced glycation endproducts, important mediators of chronic complications of diabetes mellitus. Ann NY Acad Sci. 2008;1150:311-5.

33. Barrett ML, Udani JK. A proprietary alpha-amylase inhibitor from white bean (Phaseolus vulgaris): a review of clinical studies on weight loss and glycemic control. Nutr J. 2011;10:24.

34. Baintner K, Kiss P, Pfüller U, et al. Effect of orally and intraperitoneally administered plant lectins on food consumption of rats. Acta Physiol Hung. 2003; 90(2):97-107. 